\title{
Low zinc levels at clinical admission associates with poor outcomes in COVID-19
}

Marina Vogel-González ${ }^{* 1}$, Marc Talló-Parra ${ }^{* 2}$, Víctor Herrera-Fernández ${ }^{1}$, Gemma PérezVilaró $^{2}$, Miguel Chillón ${ }^{3,4,5}$,Xavier Nogués ${ }^{6}$, Silvia Gómez-Zorrilla ${ }^{7}$, Inmaculada LópezMontesinos $^{7}$, Judit Villar ${ }^{7}$, Maria Luisa Sorli-Redó ${ }^{7}$, Juan Pablo Horcajada ${ }^{7}$, Natalia GarcíaGiralt $^{6}$, Julio Pascual ${ }^{8}$, Juana Díez ${ }^{2 \mathbb{I}}$, Rubén Vicente ${ }^{1 \mathscr{I}}$, Robert Güerri-Fernández ${ }^{6 \mathscr{I}}$

1 Laboratory of Molecular Physiology, Department of Experimental and Health Sciences, Universitat Pompeu Fabra, Barcelona, Spain.

2 Molecular Virology Group, Department of Experimental and Health Sciences, Universitat Pompeu Fabra, Barcelona, Spain.

3 Department of Biochemistry and Molecular Biology and Institute of Neurosciences, Edifici H, Universitat Autònoma de Barcelona, E-08193, Bellaterra, Spain.

4 Unitat Mixta UAB-VHIR, Vall d'Hebron Institut de Recerca (VHIR), Barcelona, Spain.

5 Institut Català de Recerca i Estudis Avançats (ICREA), Barcelona, Spain.

6 Institut Mar d'Investigacions Mediques, Barcelona, Spain; Department of Internal Medicine, Hospital del Mar, Autonomous University of Barcelona, Spain; CIBERFES, Instituto Carlos III, Madrid, Spain.

7 Institut Mar d'Investigacions Mediques, Barcelona, Spain; Department of Infectious Diseases, Hospital del Mar, Autonomous University of Barcelona, Spain; CIBERFES, Instituto Carlos III, Madrid, Spain.

8 Institut Mar d'Investigacions Mediques, Barcelona, Spain; Department of Nephrology, Hospital del Mar, Autonomous University of Barcelona, Spain.

* both authors contributed equally to the work

II JD, RV and RGF are joint senior authors in this work

Brief title: "Zinc levels impacts on COVID-19 outcomes"

\section{Corresponding Author:}

Robert Güerri-Fernández MD, PhD

Hospital del Mar Institute of Medical Research. IMIM.

Passeig Doctor Aiguader 88

Email: rguerri@psmar.cat

Tel : +34 932483251 


\begin{abstract}
Background: Biomarkers to predict Coronavirus disease-19 (COVID-19) outcome early at infection are urgently needed to improve prognosis and treatment. Zinc balances immune responses and also has a proven direct antiviral action against some viruses. Importantly, zinc deficiency (ZD) is a common condition in elderly and individuals with chronic diseases, two groups with more severe COVID-19 outcomes. We hypothesize that serum zinc content (SZC) influences COVID-19 disease progression and thus might represent a useful biomarker.

Methods: We run a retrospective observational study with 249 COVID-19 patients admitted in Hospital del Mar. We have studied COVID-19 severity and progression attending to SZC at admission. In parallel we have studied SARS-CoV2 replication in the Vero E6 cell line modifying zinc concentrations.

Findings: Our study demonstrates a correlation between serum zinc levels and COVID-19 outcome. Serum zinc levels lower than $50 \mu \mathrm{g} / \mathrm{dl}$ at admission correlated with worse clinical presentation, longer time to reach stability and higher mortality. Our in vitro results indicate that low zinc levels favor viral expansion in SARS-CoV2 infected cells.

Interpretation: SZC is a novel biomarker to predict COVID-19 outcome. We encourage performing randomized clinical trials to study zinc supplementation as potential prophylaxis and treatment with people at risk of zinc deficiency.

Funding: Spanish Ministry of Science and Innovation, "Maria de Maeztu" Programme for Units of Excellence in R\&D and Secretaria d'Universitats i Recerca del Departament d'Economia i Coneixement of the Generalitat de Catalunya. Instituto Carlos III Fondos de Investigaciones Sanitarias (FIS), CIBER on Frailty and Healthy Ageing and FEDER funds
\end{abstract}




\section{INTRODUCTION}

Infections with SARS-CoV-2 result in a systemic disease with a variety of outcomes, from no symptoms to severe and diverse pathologies, being pneumonia and acute distress the most common. Therefore, biomarkers to predict disease severity in early infection stages are urgently needed.

Zinc $\left(\mathrm{Zn}^{2+}\right)$ is an essential trace element required for maintaining a variety of fundamental biological processes due to its functions as a cofactor, signaling molecule, and structural element. One of the most significant roles of zinc in our body is its broad effect on the immune system ${ }^{1,2}$, as both, the adaptive and the innate immunity, are affected by zinc levels. Consequently, zinc deficiency (ZD), due to low zinc intake and/or malabsorption, results in an immune imbalance that ultimately causes a major public health problem with high prevalence in elderly and individuals with chronic diseases ${ }^{1}$. In adaptive immunity, zinc affects $\mathrm{T}$ lymphocyte maturation, differentiation and cytokine production. B cells activation and plasma cell differentiation depend on zinc signaling as well ${ }^{2,3}$. In innate immunity, zinc has an anti-inflammatory role ${ }^{4}$. Concretely, $\mathrm{ZD}$ is associated with higher levels of IL-1beta and TNF-alfa (5) and with altered activities of monocytes, neutrophils and NK cells ${ }^{4,6,7}$. Correspondingly, ZD results in increased susceptibility to inflammatory and infectious diseases including acquired immune deficiency syndrome, measles, malaria, tuberculosis, and pneumonia (Reviewed $\mathrm{in}^{2}$ ).

In this context, zinc supplementation trials have been carried out to reduce morbidity and mortality in developing countries with high ZD incidence. Importantly, zinc supplementation significantly reduced the duration of respiratory tract infections caused by rhinoviruses and coronaviruses $^{8}$. Moreover, zinc has been shown to have a direct antiviral action (reviewed in ${ }^{9}$ ). Remarkably, zinc inhibited in vitro both, the binding of the SARS coronavirus RNA-dependent RNA polymerase to its template and the subsequent elongation, and viral replication in cell culture $^{10}$. Altogether, zinc status might condition COVID-19 severity and zinc supplementation could be a useful tool to impact COVID-19 outcome.

In this work we focus our observational study on the putative association between zinc status of hospitalized COVID-19 patients with disease progression and clinical outcomes. Moreover, we address in cell culture the potential of zinc supplementation to directly block SARS-CoV-2 multiplication in Vero E6 infected cells.

\section{METHODS}

\section{Study design and participants}

A retrospective observational cohort study was performed at Hospital del Mar in Barcelona (Spain). This is a 400-bed university tertiary hospital in Barcelona that provides healthcare to an urban area of 500,000 people. All patients admitted with COVID-19 for $\geq 48 \mathrm{~h}$ between $9^{\text {th }}$ March and $1^{\text {st }}$ April 2020 were included. COVID-19 was defined as a SARS-CoV-2 infection confirmed by quantitative PCR (qPCR) performed in nasopharyngeal samples obtained by trained personnel at hospital admission, and/or by fulfilling clinical diagnostic criteria. These include any of the following: respiratory symptoms (dyspnea, cough, sore throat, changes in taste/smell) chest X-Ray findings (uni- or bilateral interstitial infiltrates) that made the diagnosis 
probable in the current epidemiological situation. The Institutional Ethics Committee of Hospital del Mar of Barcelona approved the study and due to the nature of the retrospective data review, and waived the need for informed consent from individual patients (CEIm 2020/9352).

\section{Procedures}

Demographic, clinical, epidemiological and the whole episode (laboratory workout, vital signs, treatment) data were extracted from the electronic medical record using a standardized data collection method.

Laboratory workouts were systematized with an at-admission protocol that included a fasting blood draw complete kidney and liver profile, electrolytes, blood count, coagulation profile, inflammatory markers (interleukin-6 (IL-6), serum ferritin), D-dimer, myocardial enzymes, zinc and selenium levels.

\section{Definitions}

Time to clinical stability (TCS)

TCS was defined as the time elapsed since the patient's admission to: oxygen saturation $>94 \%$ (FiO2 21\%), normalized level of consciousness (baseline), Heart Rate <100rpm, systolic Blood Pressure $>90 \mathrm{~mm} \mathrm{Hg}$, temperature $<37 \cdot 2 \mathrm{C}$.

\section{Clinical severity}

Clinical severity was assessed at admission with Modified Early Warning Score (MEWS) ${ }^{11}$. The same score was used for the follow-up during the admission.

\section{Zinc deficit}

According to previous publications the threshold of $\mathrm{Zn}^{2+}$ considered abnormally lower was 50 $\mu \mathrm{g} / \mathrm{dl}(7.6 \mu \mathrm{M})(12)$ This cutoff was set to categorize $\mathrm{Zn}^{2+}$ levels. We considered as predictive factor the lower range $(<50 \mu \mathrm{g} / \mathrm{dl})$.

\section{Cell culture}

Vero E6 cells were grown as described ${ }^{13,14}$. When indicated, FBS was incubated according to the manufacturer's instructions with Chelex 100 resin (Bio-Rad Laboratories) to generate $\mathrm{Zn}^{2+}$-free growth medium. $\mathrm{ZnSO}_{4}$ was added as needed to the final medium to generate specific $\mathrm{Zn}^{2+}$ concentration conditions. Chloroquine (Supelco, \#PHR1258) was prepared in water at $10 \mathrm{mM}$ and used at the desired concentration.

\section{Zinc measurements}

Cells were seeded and grown in multi well 24 plates until reaching $80 \%$ of confluence. Cells were incubated with $1 \mu \mathrm{M}$ of FluoZin-3AM (Invitrogen) or $25 \mu \mathrm{M}$ of Zinquin (Sigma-Aldrich) for $30 \mathrm{~min}$ at $37^{\circ} \mathrm{C}\left(5 \% \mathrm{CO}_{2}\right)$ in isotonic solution containing (in $\left.\mathrm{mM}\right) 140 \mathrm{NaCl}, 5 \mathrm{KCl}, 1.2$ $\mathrm{CaCl}_{2}, 0.5 \mathrm{MgCl}_{2}, 5$ glucose, and 10 Hepes (300 milliosmoles/liter, $\mathrm{pH}$ 7.4) plus different concentrations of $\mathrm{Zn}^{2+}$ and/or Chloroquine (CQ). Cells were then dissociated with Trypsin 0.05\% in $0.53 \mathrm{mM}$ EDTA and were washed with PBS 1x. Fluorescence was quantified using a LSRII flow cytometer. Further analysis was performed using Flowing Software (Perttu Terho). 
For in vivo confocal imaging, cells growth on $22 \mathrm{~mm}$ coverslips were incubated with Lysotracker

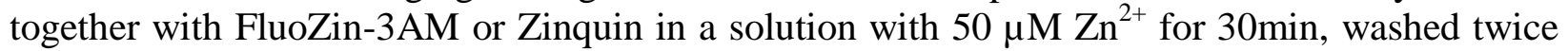
with PBS and placed under the microscope in isotonic solution for imaging with a SP8 Leica microscope.

\section{Viability assays}

Cells were exposed to different $\mathrm{Zn}^{2+}$ and CQ concentrations for $48 \mathrm{~h}$. Then, MTT reagent was added to obtain a final concentration of $0.5 \mathrm{mg} / \mathrm{ml}$. Cells were incubated $2-3 \mathrm{~h}$ at $37^{\circ} \mathrm{C}$. After that, supernatant was removed and cells were resuspended in $100 \mu \mathrm{l}$ of DMSO. The absorbance was read at $570 \mathrm{~nm}$.

\section{Virus infection and quantification}

Vero E6 cells were infected with SARS-CoV-2 strain hCoV-19/Spain/VH000001133/2020 (EPI_ISL_418860) and $48 \mathrm{~h}$ later viral RNA from the supernatant was extracted using the QuickRNA Viral Kit (Zymo Research). SARS-CoV-2 production was quantified by qPCR with the qScript $^{\text {TM }}$ XLT One-Step RT-qPCR ToughMix®, ROX ${ }^{\mathrm{TM}}$ (Quanta Biosciences) using the following specific probe: 2019-nCoV_N1-P, 5'-FAM-ACCCCGCATTACGTTTGGTGGACCBHQ1-3'; and primers: 2019-nCoV_N1-F, 5'-GACCCCAAAATCAGCGAAAT-3'; and 2019nCoV_N1-R, 5'-TCTGGTTACTGCCAGTTGAATCTG-3' (Biomers).

\section{Western blot}

Cells were treated with 0,10 or $50 \mu \mathrm{M}$ of $\mathrm{Zn}^{2+}$ and $10 \mu \mathrm{M}$ of $\mathrm{CQ}$ for $24 \mathrm{~h}$. Then, cells were washed twice with cold PBS and lysed with $35 \mu \mathrm{l}$ of lysis buffer ( $50 \square \mathrm{mM}$ Tris- $\mathrm{HCl} \mathrm{pH} 7 \cdot 4$,

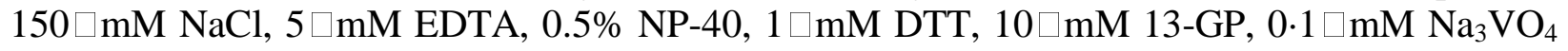
and protease inhibitors). Lysates were vortex for $30 \mathrm{~min}$ at $4^{\circ} \mathrm{C}$ and centrifuged at $10000 \mathrm{x} g$ to remove aggregates. Lysates were boiled at $95{ }^{\circ} \mathrm{C}$ and placed $1 \mathrm{~min}$ in ice. $20 \mu \mathrm{l}$ of each sample were loaded onto a 12 or $14 \%$ polyacrylamide gel. After transfer, membranes were blocked with $5 \%$ of milk in TBS-Tween $0.1 \%$ for $1 \mathrm{~h}$ at room temperature. Primary antibodies were diluted in blocking solution: LC3 (L8918, Sigma) at 1:500; p62 (ab155686, Abcam) at 1:1000; GAPDH (ab8245, Abcam) at 1:1000; and incubated overnight at $4^{\circ} \mathrm{C}$. Anti-rabbit or anti-mouse HRP secondary antibodies (1:1000; GE Healthcare) were used.

\section{Statistical analysis}

A descriptive analysis of the main demographic characteristics of the cohort, and the main clinical (laboratory, treatment and outcome) characteristics of the episode was done. Continuous and categorical variables were presented as median (interquartile range (IQR)) and absolute number (percentage), respectively. Mann-Whitney U-test, $\chi 2$ test and Fisher's exact test were used to compare differences between individuals with serum zinc levels above and below 50 $\mu \mathrm{g} / \mathrm{ml}$ respectively. Bi-variate comparisons and a multiple logistic regression model studying the impact of at admission serum zinc in in-hospital mortality were fitted adjusting by age, sex, comorbidities and severity of the episode. Taking into consideration the number of deaths observed and to avoid overfitting the model we selected the most significant variables and those that provided a more general characterization of the individuals. We excluded variables if they 
had collinearity with MEWS, or age. Significance was a p-value <0.05. Stata 14 software was used.

In the in vitro assays, we applied either unpaired Student's $t$ test (when comparing two conditions) and one-way analysis of variance (ANOVA) followed by Bonferroni post hoc test (when comparing control with any other condition) were applied. All plots comparisons and $\mathrm{p}$ values are described in figure legends. Analysis was performed using GraphPad software.

\section{RESULTS}

We included 249 consecutive adults admitted to the COVID-19 unit between March $9^{\text {th }}$ and April $1^{\text {st }}, 2020$. The median age of participants was 65 (54-75) years, $49 \%$ were female. Table 1 shows the baseline characteristics of the cohort and the differences between individuals with SZC $<50 \mu \mathrm{g} / \mathrm{dl}$ and $\geq 50 \mu \mathrm{g} / \mathrm{dl}$ at onset. Hypertension was the most prevalent comorbidity. At admission the overall severity according to MEWS score was 2 (1-3). Fever, cough and dyspnea were the most common symptoms with a frequency of $203(81 \%), 198(79 \%)$ and $151(60 \%)$ respectively. Inflammation was a hallmark of the episode with $224(87.5 \%)$ of individuals with an abnormal IL-6 at admission and with a median IL-6 42pg/ml (15-89), a median C-ReactiveProtein $7.5 \mathrm{mg} / \mathrm{dl}$ (3.5-15.2), and a median D-Dimer $800 \mathrm{UI} / \mathrm{l}$ (470-1450). Almost all the individuals admitted during this period received hydroxychloroquine. Other treatments were tocilizumab, dexamethasone and methylprednisolone that were prescribed in a quarter of individuals each one. 70 patients (28\%) were admitted to the ICU and 21 (9\%) patients died during hospitalization in this period.

SZC median at admission were $61 \mu \mathrm{g} / \mathrm{dl}(9 \cdot 3 \mu \mathrm{M})$ with $58(23 \%)$ of the individuals presenting SZC $<50 \mu \mathrm{g} / \mathrm{dl}$. Individuals with serum zinc levels $<50 \mu \mathrm{g} / \mathrm{dl}$ had higher prevalence of chronic kidney disease and chronic respiratory disease $9 \%$ vs $2 \% ; \mathrm{p}=0.024$ and $16 \%$ vs $7 \%$; $\mathrm{p}=0.041$. Moreover, this group had a more severe clinical presentation MEWS score (2 (2-3) vs 2 (1-3); $\mathrm{p}=0.005)$ and a significantly higher inflammation measured by the nonspecific marker $\mathrm{C}$ Reactive protein $14.6 \mathrm{mg} / \mathrm{dl}$ vs $7 \mathrm{mg} / \mathrm{dl}$; $\mathrm{p}=0.03$ and the more specific one IL-6 $77 \mathrm{pg} / \mathrm{ml}$ vs $32 \mathrm{pg} / \mathrm{ml} ; \mathrm{p}<0 \cdot 001$. At admission, SZC correlated negatively with inflammation measured by IL6 (Pearson's $\mathrm{r}=-0.307$; $\mathrm{p}<0.001$ ) (Fig 1A) and, interestingly also correlated with the highest value of IL-6 during the episode (Pearson's $r=-0 \cdot 317 ; \mathrm{p}<0 \cdot 001$ ) (Fig 1B). This negative correlation was also observed with the nonspecific inflammatory markers such as ferritin (Pearson's r=-0.227; p=0.001) and C-Reactive Protein (Pearson's r=-0.315; p<0.001) (Fig 1C). We also found correlation between SZC at admission and procoagulation factors such as Ddimer (Pearson's $\mathrm{r}=-0 \cdot 317$; $\mathrm{p}=0 \cdot 048$ ).

The median time to reach clinical stability in our cohort was 9.5 days (6-18). However, subjects with SZC at admission $<50 \mu \mathrm{g} / \mathrm{dl}$ needed longer TCS stability compared with those with zinc $\geq 50 \mu \mathrm{g} / \mathrm{dl}, 25$ days (14-36) vs 8 (5-14) days, respectively; $\mathrm{p}<0 \cdot 001$. Moreover, SZC at admission was correlated negatively with TCS of the episode (Pearson's $r=-0.441 ; p<0 \cdot 001$ ) (Fig 1D). In a multivariable linear regression model adjusted by age, sex, severity and comorbidities TCS was associated with low SZC at admission (beta-coefficient -0.21 (95\% CI -0.316 to -0.097 ; $\mathrm{p}<0.001)$ ). In an alternative model, serum zinc levels $<50 \mu \mathrm{g} / \mathrm{dl}$ negatively impacted on TCS (beta-coefficient 14.1 (95\% CI 4.29 - 23.94; p=0.004). 
Twenty-one individuals (9\%) died during this period. SZC at admission was significantly higher among individuals who survived $62 \mu \mathrm{g} / \mathrm{dl}$ (52-72) compared to those who died $49 \mu \mathrm{g} / \mathrm{dl}$ (42-53); $\mathrm{p}<0 \cdot 001$. Individuals with $\mathrm{SZC}$ at admission $<50 \mu \mathrm{g} / \mathrm{dl}$ had a mortality of $21 \%$ that was significantly higher compared with $5 \%$ mortality in individuals with zinc at admission $\geq 50 \mu \mathrm{g} / \mathrm{dl}$; $\mathrm{p}<0.001$. We fitted a multivariable logistic regression model including 249 patients with data for all variables (228 survivors and 21 non-survivors). When adjusting by age, sex, Charlson comorbidity index and severity, the model showed an odds ratio (OR) for in-hospital death of 0.94 [95\% CI 0.899 to 0.982 ; $\mathrm{p}=0.006$ ) per unit increase of serum zinc at admission. In an alternative adjusted model with the predictive variable SZC at admission $<50 \mu \mathrm{g} / \mathrm{dl}$ the adjusted OR for in-hospital death was $3 \cdot 2(95 \%$ CI $1 \cdot 01$ to $10 \cdot 12$; $\mathrm{p}=0 \cdot 047)$.

To further understand the link between zinc status and COVID-19 severity, we carried out assays in cell culture to study the direct impact of cellular zinc content on SARS-CoV-2 multiplication. We used three different concentrations of zinc in the extracellular medium, 0,10 and $50 \mu \mathrm{M}$ $\mathrm{ZnSO}_{4}$, to reproduce zinc deficiency, physiological zinc and zinc supplementation, respectively. As expected, intracellular $\mathrm{Zn}^{2+}$ content changed in Vero E6 cells incubated for 30min in different extracellular $\mathrm{Zn}^{2+}$ concentrations and monitored with Fluozin 3AM and Zinquin fluorescence probes. Confocal images showed that FluoZin 3AM signal was mainly localized in the lysosomal compartment while Zinquin signal was intracellularly spread (Fig 2B). After 48h incubation, different $\mathrm{Zn}^{2+}$ content solutions did not impact cell viability (Fig 2C). Importantly, extracellular zinc concentrations affected SARS-CoV-2 multiplication as measured by qPCR from the cell culture supernatant at $48 \mathrm{~h}$ post infection. SARS-CoV-2 multiplication was increased at $0 \mu \mathrm{M}$ $\mathrm{Zn}^{2+}$ when compared to those values at 10 and $50 \mu \mathrm{M} \mathrm{Zn}{ }^{2+}$ concentrations (Fig 2D). This indicates that zinc levels affect the SARS-CoV-2 life cycle in infected cells.

It has been suggested that $\mathrm{Zn}^{2+}$ may potentiate CQ antiviral activity ${ }^{15}$. To test this, we carried out SARS-CoV-2 infections at different zinc concentrations in the absence or presence of $10 \mu \mathrm{M}$ $\mathrm{CQ}$, the concentration chosen based on previous published effective concentration ${ }^{13,14}$. Neither the CQ toxicity nor its antiviral activity were affected by zinc levels (Fig 3A,B). CQ caused a significant reduction in SARS- CoV- 2 RNA genome copies compared to control cells $(59.68 \pm 18.46 \% ; \mathrm{p}<0.05)$ (Fig 3B). Next, we addressed whether CQ increases the intracellular $\mathrm{Zn}^{2+}$ content by acting as a zinc ionophore, as was previously proposed ${ }^{16}$. For this, we evaluated the cytosolic $\mathrm{Zn}^{2+}$ levels in cells growth under different CQ concentrations using flow cytometry analysis and FluoZin-3AM and Zinquin labels (Fig 3C). Notably, an increased zinc signal was observed in a CQ dose dependent manner using FluoZin-3AM but not with Zinquin (Fig 3C). This indicates that CQ modifies lysosomal $\mathrm{Zn}^{2+}$ content but it is not a zinc ionophore. As the described increase in lysosomal $\mathrm{pH}$ caused by CQ blocks autophagic flux (17) and inhibition of autophagy impairs SARS-CoV-2 replication ${ }^{18}$, we studied the impact on autophagy of different zinc concentrations in the presence and the absence of CQ (Fig 3D-F). As expected, at 10 $\mu \mathrm{M}$ CQ treatment autophagy blockade resulted in an increased LC3II/I ratio and p62 expression (Fig $3 \mathrm{E}, \mathrm{F})$. However, no significant effects on these values were observed at different $\mathrm{Zn}^{2+}$ levels in the absence or presence of CQ. Altogether, our results indicate that CQ and zinc do not potentiate each other. 


\section{DISCUSSION}

Our study demonstrates a correlation between serum zinc levels and COVID-19 outcome. SZC lower than $<50 \mu \mathrm{g} / \mathrm{dl}$ at admission correlated with worse clinical presentation, longer time to reach stability and higher mortality. These results point at SZC as an early predictor of COVID19 severity, whose adjustment might also constitute an early therapeutic intervention point. Moreover, we show that SZC affects the SARS-CoV-2 life cycle in the infected cells. This effect, contrary to what it was previously suggested, does not seem to potentiate CQ activity.

The association between SZC and human health is known for decades ${ }^{1}$. Due to poor nutrition and subsequent low zinc intake, ZD remains a major nutritional problem in multiple countries. In addition, elderly individuals are prone to ZD even in developed countries where the incidence ranges from 15 to $31 \%$ depending on the age and the country of study ${ }^{19}$. Older adults are the group at higher risk for severe symptoms and mortality from COVID-19. In our retrospective observational study with 249 COVID-19 patients admitted to Hospital del Mar, 23\% of them had at admission SZC lower than 50 $\mathrm{g} / \mathrm{dl}$, the cutoff associated with ZD and development of clinical signs $^{12}$.

At onset, higher levels of inflammatory markers such as IL-6 and C-reactive protein were present in low SZC patients (Fig 1A,C). The prognostic value for COVID-19 severity of IL-6 and Creactive protein has already been described ${ }^{13}$. In this work we highlight the importance of SZC as an early predictor of COVID-19 severity and clinical outcome, and consequently, as a potential therapeutic intervention point. ZD is known to be associated with proinflammatory responses at infection, showing higher reactive oxygen species production and inflammatory markers ${ }^{20,21}$. An imbalance in cytokine production by cells of both innate and adaptive immunity has also been reported $^{3,2}$. In our study, we observed a robust negative correlation between zinc levels and IL-6 (Fig 1B). In this respect, it has been reported that IL-6 potentiates SZC decrease by promoting zinc internalization in hepatocytes in acute phase of infection ${ }^{22}$. We cannot discard that the hypozincemia observed in COVID-19 patients might be caused and worsened by a negative IL-6 production loop.

Several clinical trials using zinc supplementation have been carried out to prevent and treat infections and inflammatory conditions ${ }^{1,2}$. Zinc supplementation decreases the incidence of infection in elderly and improves cytokine imbalance and oxidative stress markers ${ }^{23,24}$. Thus, the idea of supplementing low SZC COVID-19 patients with zinc in order to balance what has been called the cytokine storm caused by SARS-CoV-2 is attractive. Reassuringly, zinc supplementation for the common cold caused by rhino- and coronaviruses has been proven to reduce its duration and symptoms. In addition to the impact of zinc in the modulation of the antiviral immune response, zinc has also been shown to have a direct antiviral action ${ }^{9}$. We have analyzed in vitro the impact of zinc homeostasis in SARS-CoV-2 infection. Our results indicate that hypozincemia favors viral expansion in the infected cell (Fig 2C). These results would support that the poor clinical outcome observed in low SZC patients is caused by the effect of ZD on both, inducing immune imbalance and increasing viral load via promoting viral expansion in the infected cell. Of note, our in vitro studies, however, did not show a replication blockade in zinc supplementation conditions $(50 \mu \mathrm{M}$, Fig $2 \mathrm{C})$ suggesting the need of a zinc ionophore to 
further increase cytosolic zinc levels as previously shown in vitro for Herpes simplex, picornavirus, arterivirus and SARS-CoV coronavirus ${ }^{9,10}$.

During the beginning of the pandemic CQ was prescribed as a first line treatment in the acute presentation. The rationale was that CQ has been claimed to be a novel zinc ionophore ${ }^{16}$ and CQ showed antiviral effects against SARS-CoV-2 in vitro ${ }^{13,14}$. However, clinical trials failed to demonstrate beneficial effect over COVID-195,26. Therefore, it was suggested that zinc supplementation could potentiate its antiviral activity ${ }^{15}$. In our results in vitro, cellular zinc content did not modify CQ cytotoxicity, the autophagic flux blockade or its antiviral action against SARS-CoV2. Moreover, we monitored intracellular zinc content both with Fluozin$3 \mathrm{AM}$, a probe previously done by Xue and colleagues that is retained mainly in lysosomes ${ }^{16}$, and with Zinquin, which presents a more general intracellular staining. We conclude that CQ is not a zinc ionophore as previously claimed because its effect on cellular zinc content is restricted to the lysosomal compartment, probably by altering zinc transport at this specific organelle (Fig 3). Thus, our study does not support the mechanistic rationale of supplementing CQ treatments with zinc.

This work aims to focus clinical attention on serum zinc content in COVID-19 patients. Our analysis has shown a robust correlation between low SZC and COVID-19 severity and mortality. The cause is likely to be a combination of immune system imbalance and a direct benefit of viral replication. Thus, we propose SZC as a novel parameter to predict COVID-19 outcome. It is then urgent to start clinical trials supplementing with zinc low SZC patients at admission to reestablish zinc homeostasis. It should be also recommended to promote zinc supplementation programs targeted to people at risk of zinc deficiency, such as elderly, in order to reduce COVID-19 severity.

\section{ACKNOWLEDGEMENTS}

This work was supported by the Spanish Ministry of Science and Innovation through grants PID2019-106755RB-I00/AEI/10.13039/501100011033 to RV and PID2019-106959RB-I00/AEI /10.13039/501100011033 to JD, an institutional "Maria de Maeztu" Programme for Units of Excellence in R\&D (CEX2018-000792-M) to RV and JD and by the 2017 SGR 909 grant from the Secretaria d'Universitats i Recerca del Departament d'Economia i Coneixement of the Generalitat de Catalunya to JD. RGF received support and funding from Centro de Investigación Biomédica en Red de Fragilidad y Envejecimiento Saludable (CIBERFES) [Grant number CB16/10/00245], FEDER funds and the FIS Project from Instituto de Salud Carlos III, Ministerio de Ciencia e Innovación [Grant number (PI19/00019)]

\section{DECLARATION OF INTERESTS}

The authors declare that no competing interests exist 


\section{FIGURE LEGENDS}

Figure 1. Correlation between serum zinc levels at admission, inflammatory markers and clinical outcome. A. Zinc and IL-6 at admission. B. Zinc at admission and highest value of IL-6 during the episode. C. Zinc and C-Reactive Protein at admission. D. Serum zinc content at admission and time to clinical stability.

Figure 2. Evaluation of zinc homeostasis in SARS-CoV2 infection. A-B. Intracellular zinc content measurement using FluoZin-3AM and Zinquin probes in Vero E6 cells. A. Flow cytometry in cells incubated for $30 \mathrm{~min}$ with 0,10 and $50 \mu \mathrm{M}$ extracellular $\mathrm{Zn}^{2+}$ content. Intensity expressed in Arbitrary Units (AU) $(n=3 ; * \mathrm{p}<0.05$, *** $\mathrm{p}<0.001$; Bonferroni-corrected one-way ANOVA compared to $0 \mathrm{Zn}^{2+}$ ). B. Confocal images of living cells incubated with FluoZin-3AM

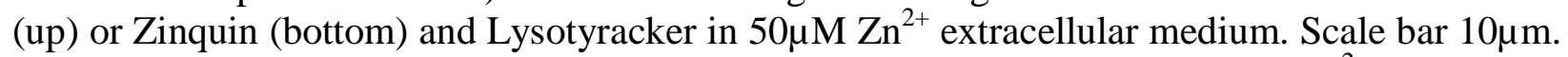
C. Viability MTT assay in cells incubated with 0,10 and $50 \mu \mathrm{M}$ extracellular $\mathrm{Zn}^{2+}$ content for 48h. Data expressed in percentage compared to control condition $\left(10 \mu \mathrm{M} \mathrm{Zn}^{2+}\right) \quad(\mathrm{n}=12$; Bonferroni-corrected one-way ANOVA compared to $10 \mu \mathrm{M} \mathrm{Zn}^{2+}$ ). D. Quantification in supernatant of viral RNA copies by qPCR in cells infected with SARS-CoV2 and collected at 48h. Data expressed in percentage compared to control condition $\left(10 \mu \mathrm{M} \mathrm{Zn}^{2+}\right)(\mathrm{n}=3 ; * * \mathrm{p}<0 \cdot 01$; Bonferroni ANOVA compared to $10 \mu \mathrm{M} \mathrm{Zn}^{2+}$ ).

Figure 3. Evaluation of zinc potentiation of chloroquine antiviral action. A. Viability MTT assay in cells incubated with $10 \mu \mathrm{M} C Q$ in 0,10 and $50 \mu \mathrm{M} \mathrm{Zn}^{2+}$ content for $48 \mathrm{~h}(\mathrm{n}=15$; Bonferroni-corrected one-way ANOVA compared to $10 \mu \mathrm{M} \mathrm{Zn}^{2+}$ ). B. Quantification in supernatant of viral RNA copies by qPCR in cells infected with SARS-CoV2 treated with $10 \mu \mathrm{M}$

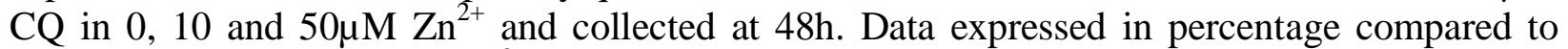
control condition $\left(10 \mu \mathrm{M} \mathrm{Zn}{ }^{2+}\right.$ without CQ, Fig 2D) $(n=3$; Bonferroni-corrected one-way ANOVA compared to $10 \mu \mathrm{M}$ CQ in $10 \mu \mathrm{M} \mathrm{Zn}^{2+}$ ). C. Flow cytometry in cells incubated for $30 \mathrm{~min}$ with 0,10 and $50 \mu \mathrm{M}$ extracellular $\mathrm{Zn}^{2+}$ content using FluoZin-3AM and Zinquin probes. Intensity expressed in Arbitrary Units (AU) ( $\mathrm{n} \geq 4$; *** $\mathrm{p}<0 \cdot 001$; Bonferroni-corrected one-way ANOVA compared to $0 \mu \mathrm{M} \mathrm{Zn}^{2+}$ from each probe). D-F. Western blot analysis from cells incubated for $24 \mathrm{~h}$ in 0,10 and $50 \mu \mathrm{M} \mathrm{Zn}^{2+}$ with or without $10 \mu \mathrm{M} \mathrm{CQ}$. Antibodies against LC3, p62 and GAPDH. D. Representative blot. E-F. Quantification of the bands for LC3 (E; $n \geq 10)$

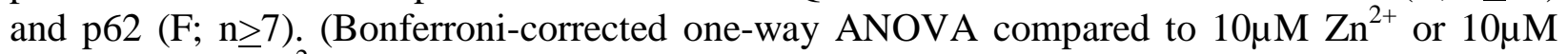
$\mathrm{CQ}$ in $10 \mu \mathrm{M} \mathrm{Zn}^{2+}$. ** $\mathrm{p}<0.01$, *** $\mathrm{p}<0.001$ unpaired t-test comparing conditions with and without CQ). 


\section{References}

1. Prasad AS. Discovery of human zinc deficiency: its impact on human health and disease. Adv Nutr. 2013;4:176-90.

2. Gammoh NZ, Rink L. Zinc in infection and inflammation. Nutrients 2017;9:624.

3. Beck FW, Prasad AS, Kaplan J, Fitzgerald JT, Brewer GJ. Changes in cytokine production and $\mathrm{T}$ cell subpopulations in experimentally induced zinc-deficient humans. Am J Physiol. 1997;272:E1002-7.

4. Jarosz M, Olbert M, Wyszogrodzka G, Katarzyna Młyniec • Librowski T. Antioxidant and anti-inflammatory effects of zinc. Zinc-dependent NF-jB signaling. Inflammopharmacol 2017;25:11-24.

5. Wessels I, Haase H, Engelhardt G, Rink L, Uciechowski P. Zinc deficiency induces production of the proinflammatory cytokines IL-1 $\beta$ and TNF $\alpha$ in promyeloid cells via epigenetic and redox-dependent mechanisms. J Nutr Biochem. 2013;24:289-97.

6. Hasan R, Rink L, Haase H. Zinc signals in neutrophil granulocytes are required for the formation of neutrophil extracellular traps. Innate Immun. 2013;19:253-64.

7. Hasan R, Rink L, Haase H. Chelation of Free $\mathrm{Zn}^{2+}$ Impairs Chemotaxis, Phagocytosis, Oxidative Burst, Degranulation, and Cytokine Production by Neutrophil Granulocytes. Biol Trace Elem Res 2016; 171:79-88.

8. Science M, Johnstone J, Roth DE, Guyatt G, Loeb M. Zinc for the treatment of the common cold: a systematic review and meta-analysis of randomized controlled trials. CMAJ 2012;184:E551-61.

9. Read SA, Obeid S, Ahlenstiel C, Ahlenstiel G. The Role of Zinc in Antiviral Immunity. Adv Nutr 2019;10:696-710.

10. te Velthuis AJW, van den Worm SHE, Sims AC, Baric RS, Snijder EJ, van Hemert MJ. $\mathrm{Zn}(2+)$ inhibits coronavirus and arterivirus RNA polymerase activity in vitro and zinc ionophores block the replication of these viruses in cell culture. PLoS Pathog 2010;6:e1001176.

11. Subbe CP, Davies RG, Williams E, Rutherford P, Gemmell L. Effect of introducing the Modified Early Warning score on clinical outcomes, cardio-pulmonary arrests and intensive care utilisation in acute medical admissions. Anaesthesia 2003;58:797-802.

12. Wessells KR, King JC, Brown KH. Development of a Plasma Zinc Concentration Cutoff to Identify Individuals with Severe Zinc Deficiency Based on Results from Adults Undergoing Experimental Severe Dietary Zinc Restriction and Individuals with Acrodermatitis Enteropathica. J Nutr 2014;144:1204-10.

13. Liu J, Cao R, Xu M, Wang X, Zhang H, Hu H, et al. Hydroxychloroquine, a less toxic derivative of chloroquine, is effective in inhibiting SARS-CoV-2 infection in vitro. Cell Discov 2020;6:16. 
14. Yao X, Ye F, Zhang M, Cui C, Huang B, Niu P, et al. In Vitro Antiviral Activity and Projection of Optimized Dosing Design of Hydroxychloroquine for the Treatment of Severe Acute Respiratory Syndrome Coronavirus 2 (SARS-CoV-2). Clin Infect Dis 2020;71:732-9.

15. Derwand R, Scholz M, Zelenko V, York N. COVID-19 outpatients - early risk-stratified treatment with zinc plus low dose hydroxychloroquine and azithromycin $\square$ : a retrospective case series study. 2020;49:1-34. Preprint Available from: https://www.preprints.org/manuscript/202007.0025/v1

16. Xue J, Moyer A, Peng B, Wu J, Hannafon BN, Ding W-Q. Chloroquine is a zinc ionophore. PLoS One 2014;9:e109180.

17. Mauthe M, Orhon I, Rocchi C, Zhou X, Luhr M, Hijlkema K-J, et al. Chloroquine inhibits autophagic flux by decreasing autophagosome-lysosome fusion. Autophagy 2018;14:1435-55.

18. Gorshkov K, Chen CZ, Bostwick R, Rasmussen L, Xu M, Pradhan M, et al. The SARSCoV-2 cytopathic effect is blocked with autophagy modulators. bioRxiv. 2020 [cited 2020 Aug 27];2020.05.16.091520. Available from: https://www.biorxiv.org/content/10.1101/2020.05.16.091520v2

19. Yasuda H, Tsutsui T. Infants and elderlies are susceptible to zinc deficiency. Sci Rep 2016;6:21850.

20. Besecker BY, Exline MC, Hollyfield J, Phillips G, Disilvestro RA, Wewers MD, et al. A comparison of zinc metabolism, inflammation, and disease severity in critically ill infected and noninfected adults early after intensive care unit admission. Am J Clin Nutr 2011;93:1356-64.

21. Wong CP, Dashner-Titus EJ, Alvarez SC, Chase TT, Hudson LG, Ho E. Zinc Deficiency and Arsenic Exposure Can Act Both Independently or Cooperatively to Affect Zinc Status, Oxidative Stress, and Inflammatory Response. Biol Trace Elem Res 2019;191:370-81.

22. Liuzzi JP, Lichten LA, Rivera S, Blanchard RK, Aydemir TB, Knutson MD, et al. Interleukin-6 regulates the zinc transporter Zip14 in liver and contributes to the hypozincemia of the acute-phase response. Proc Natl Acad Sci U S A 2005;102:6843-8.

23. Prasad AS, Beck FW, Bao B, Fitzgerald JT, Snell DC, Steinberg JD, et al. Zinc supplementation decreases incidence of infections in the elderly: effect of zinc on generation of cytokines and oxidative stress. Am J Clin Nutr 2007;85:837-44.

24. Bao B, Prasad AS, Beck FWJ, Fitzgerald JT, Snell D, Bao GW, et al. Zinc decreases Creactive protein, lipid peroxidation, and inflammatory cytokines in elderly subjects: a potential implication of zinc as an atheroprotective agent. Am J Clin Nutr 2010;91:163441.

25. Cavalcanti AB, Zampieri FG, Rosa RG, Azevedo LCP, Veiga VC, Avezum A, et al. Hydroxychloroquine with or without Azithromycin in Mild-to-Moderate Covid-19. N Engl J Med 2020 Jul 23 [cited 2020 Aug 27]; Available from: http://www.ncbi.nlm.nih.gov/pubmed/32706953

26. Boulware DR, Pullen MF, Bangdiwala AS, Pastick KA, Lofgren SM, Okafor EC, et al. A Randomized Trial of Hydroxychloroquine as Postexposure Prophylaxis for Covid-19. N Engl J Med 2020;383:517-25. 
medRxiv preprint doi: https://doi.org/10.1101/2020.10.07.20208645; this version posted October 11, 2020. The copyright holder for this preprint (which was not certified by peer review) is the author/funder, who has granted medRxiv a license to display the preprint in perpetuity. It is made available under a CC-BY-NC-ND 4.0 International license.

A

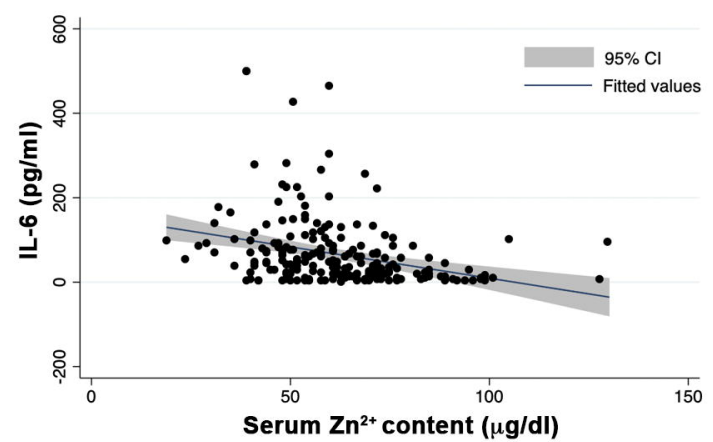

C

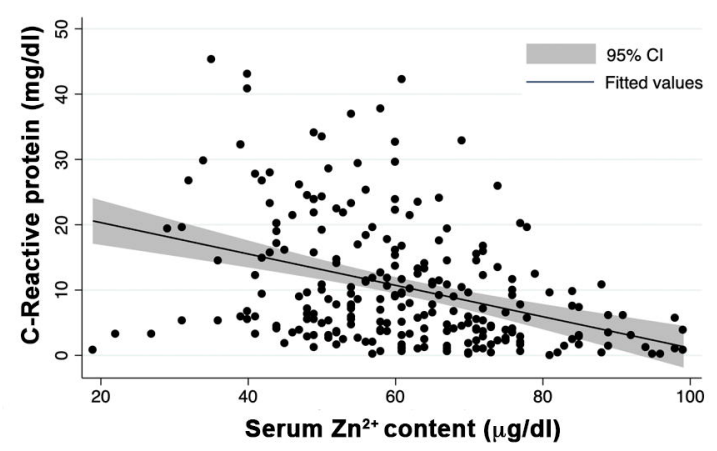

B

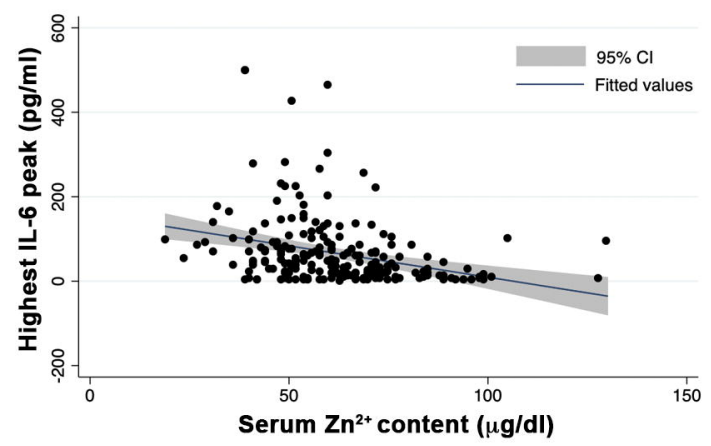

D

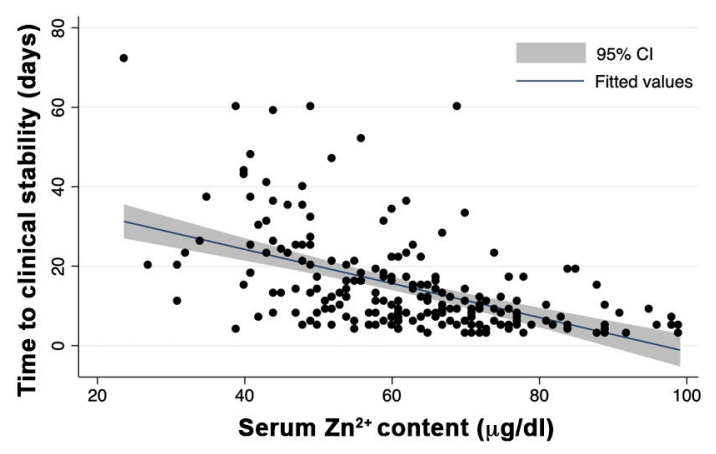




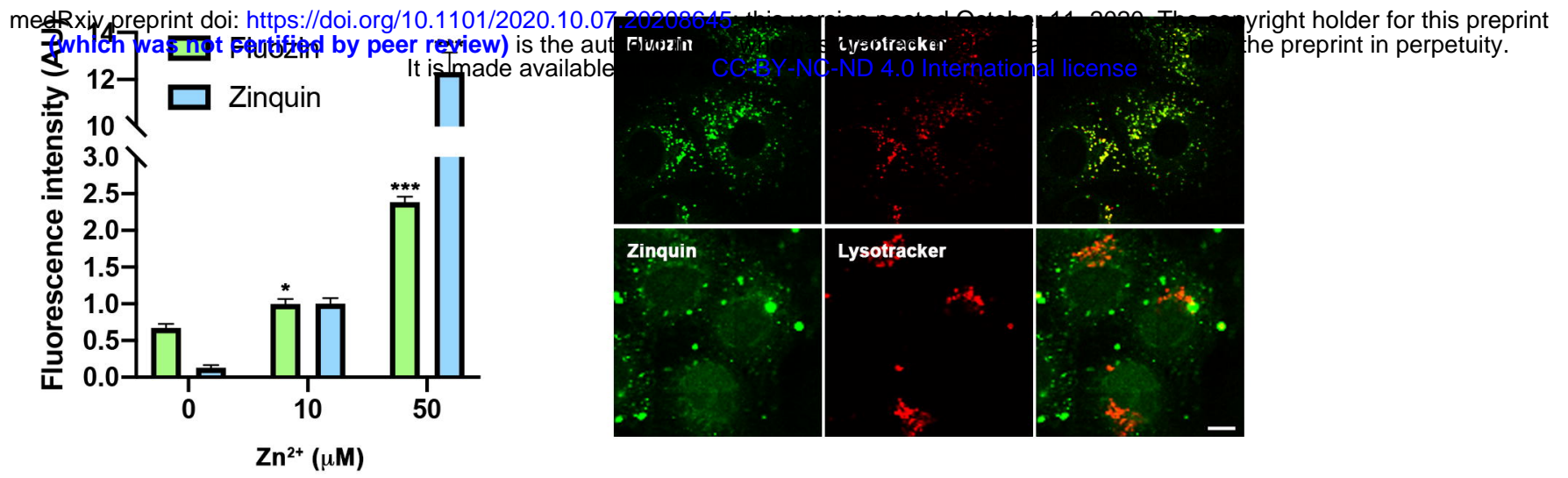

C

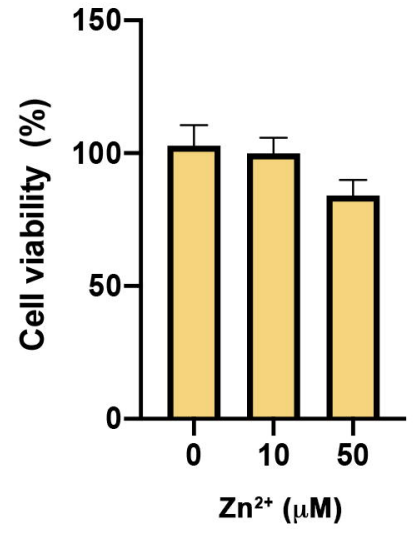

D

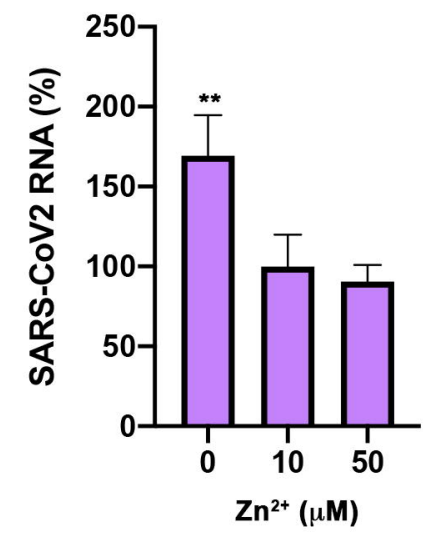


$10 \mu \mathrm{M} \mathrm{CQ}$

$10 u M C Q$

medRxiv 1 Preprint doi: https://doi.org/10.1101/2020.10.07_20208645; this version posted October $11_{3} 2020$. The copyright holder for this preprint

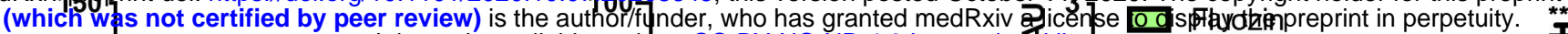

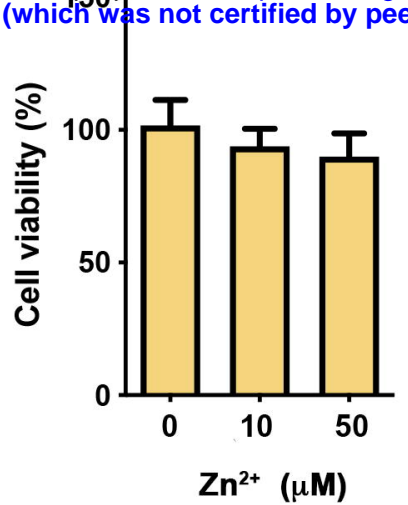
It is made availakle und $\mathrm{r}$ a CC-BY-NC-ND 4.0 Internation license.
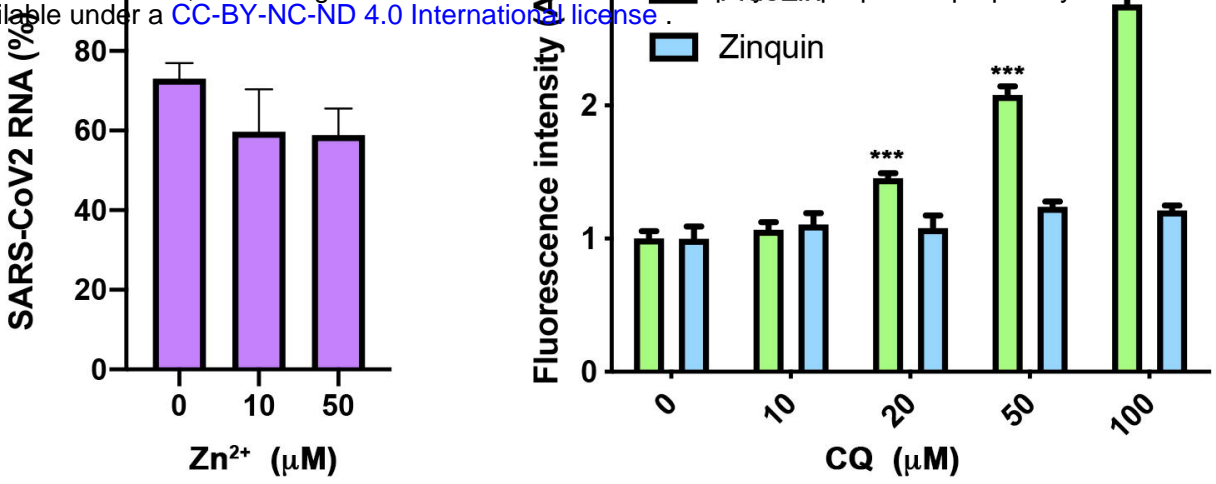

D

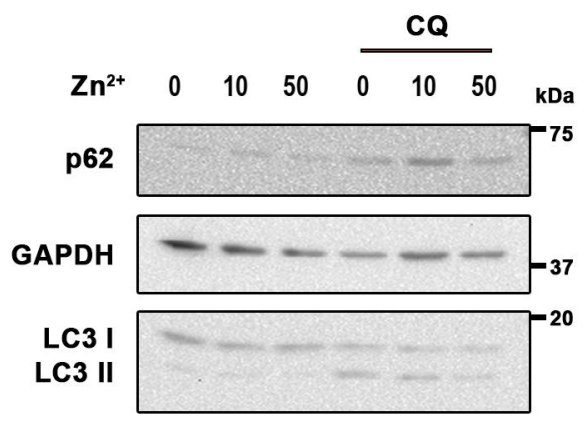

E

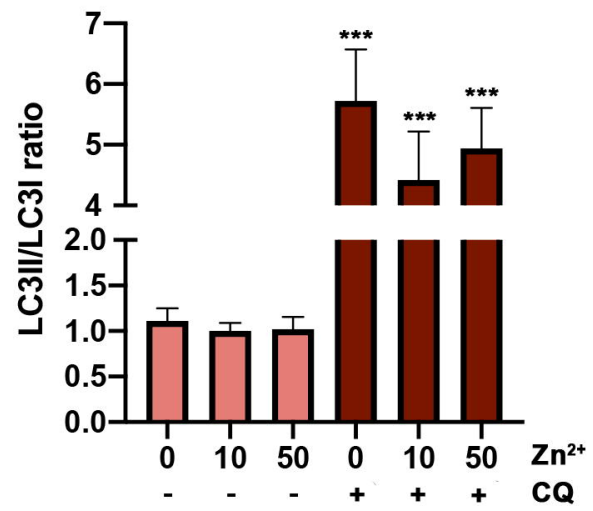

F

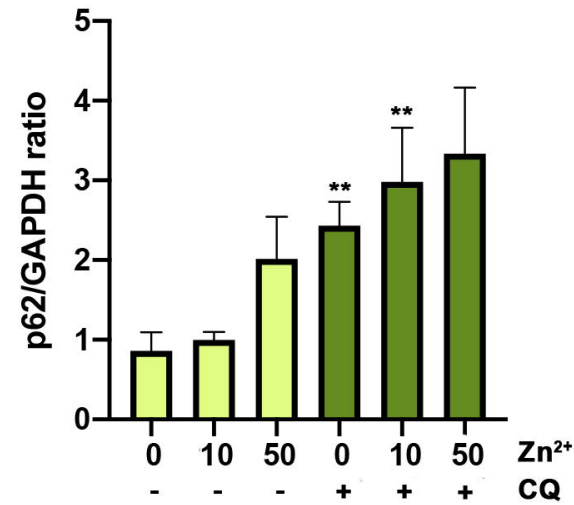

